\title{
Erratum to: Accumulation of biomass and bioenergy in culms of cereals as a factor of straw cutting height***
}

\author{
Tomasz Zajac ${ }^{1}$, Agnieszka Synowiec ${ }^{2 *}$, Andrzej Oleksy ${ }^{1}$, Jan Macuda ${ }^{4}$, Agnieszka Klimek-Kopyra ${ }^{1}$ \\ and Franciszek Borowiec ${ }^{3}$
}

${ }^{1}$ Institute of Crop Production, ${ }^{2}$ Department of Agrotechnology and Agricultural Ecology,

${ }^{3}$ Department of Animal Nutrition and Feed Management; University of Agriculture, Al. Mickiewicza 21, 31-120 Cracow, Poland ${ }^{4}$ Faculty of Drilling, Oil and Gas, Department of Oil Engineering, AGH University of Science and Technology,

Al. Mickiewicza 30, 30-059 Cracow, Poland

Received June 10, 2016; accepted March 10, 2017

\section{Corrected first author name}

Tadeusz Zajac ${ }^{1}$, Agnieszka Synowiec ${ }^{2}$, Andrzej Oleksy ${ }^{1}$,Jan Macuda ${ }^{4}$, Agnieszka Klimek-Kopyra ${ }^{1}$, and Franciszek Borowiec ${ }^{3}$ 